\title{
Tilt optimization of a double-glazed air solar collector prototype
}

\author{
Hocine Mzad ${ }^{1, *}$, Abdessalam Otmani ${ }^{1}$, Abdallah Haouam ${ }^{1}$, Stanisław Łopata ${ }^{2}$, and Paweł Ocłoń ${ }^{2}$ \\ ${ }^{1}$ Department of Mechanical Engineering, Badji Mokhtar University of Annaba, P.O. Box 12, DZ-23000, Annaba, Algeria \\ ${ }^{2}$ Institute of Thermal Power Engineering, Cracow University of Technology, Poland
}

\begin{abstract}
To understand usage of solar air collector there are factors that have influence on the performance. The goal of this paper is to investigate a solar air collector prototype in order to perform a performance optimization using the possible minimum of equations. The thermal efficiency, fluid outlet temperature, heat increase and heat losses of the collector are calculated depending on the collector geometry, fluid properties, fluid inlet temperature, air flow rate, solar insulation and ambient temperature. The calculations were performed using actual data of temperature, wind speed and the global-horizontal radiation $H_{h}$ over the year 2011 at the international airport of Annaba city. Comparison of results reveals that optimal efficacy is obtained for south facing panels with an inclination angle $\beta$ comprised in the interval $\left[15^{\circ}, 35^{\circ}\right]$. These conditions provide a useful energy exceeding $4300 \mathrm{~W}$ and an efficiency of about $51 \%$.
\end{abstract}

Keywords: Global irradiation, Panel tilt, Measured data, Optimization, Efficiency.

\section{Introduction}

The main advantages of solar air collectors are: the working fluid does not freeze or boil, they have noiseless, safely and low cost operation, they do not produce any kind of wastes and have long life cycle [1]. The solar air collectors have the following disadvantages: low density, low thermal capacity and small heat conductivity of air which lead to low thermal efficiency, high cost of production and installation and non-uniform flow [2].

The utilizability concept was originally developed by Klein and Beckman [3] for estimating the performance of flat-plate solar collectors over long time periods. In this application, low critical radiation levels are desirable in that they result in high utilizability values and thus efficient collection of solar energy.

The effect of parallel barriers on the collector efficiency of flat-plate solar air heaters has been investigated theoretically and experimentally. The theoretical predictions agree reasonably well with experimental results, Yeh and Lin [4].

In the same way, Abene et al. [5] conducted an experimental study, which consists of a solar energy simulation; they have sought to improve the efficiency temperature rise couple of the flat plate solar collector by considering several types of obstacles disposed in rows in the dynamic air vein of the flat collector.

Mzad [6] presents an approach to determine thermal parameters such as fluid temperature and efficiency of a double-glazed solar collector tested in north-western part of Algeria based on meteorological parameters collected during the year 2006.

Transient simulation program is used by Erbs et al. [7] to calculate the annual performance of solar energy systems using several correlations. A seasonally dependent daily diffuse correlation is developed from the data, and this daily relationship is used to derive a correlation for the monthly average diffuse fraction.

Comparisons between the optimal tilt angle of a collector based on the predicted monthly diffuse radiation and that based on the actual monthly diffuse radiation carried out by Tang and $\mathrm{Wu}$ [8], showed that the method in this paper gives a good estimation of the optimal tilt angle, except for the areas with a lower clearness index. Ahmad and Tiwari [9] examines the theoretical aspects of choosing a tilt angle for the solar flat plate collectors used at ten different stations in the world and makes recommendations on how the collected energy can be increased by varying the tilt angle.

In the present work a mathematical procedure of calculation was performed. Based on analytical

\footnotetext{
*Corresponding author: h_mzad@yahoo.fr
} 
formulations and empirical correlations using measured data, the study of a solar air collector was conducted to determine its performances under specific conditions. In this study we try to estimate the useful energy and the efficiency in terms of tilts and orientations of the tested solar air panel in order to achieve best desired results.

\section{Data and solar air heater specifications}

Weather is one of the meteorological data that is rich by important knowledge. The considered site is located in the North-Eastern corner of Algeria at $36^{\circ} 54^{\prime}$ North latitude and $7^{\circ} 45^{\prime}$ East longitude. The city benefits from a Mediterranean climate known for its long dry hot summers.

The wind speed hitting the solar collector has a significant influence on the estimated energy delivered by the solar air panel (Fig. 1).

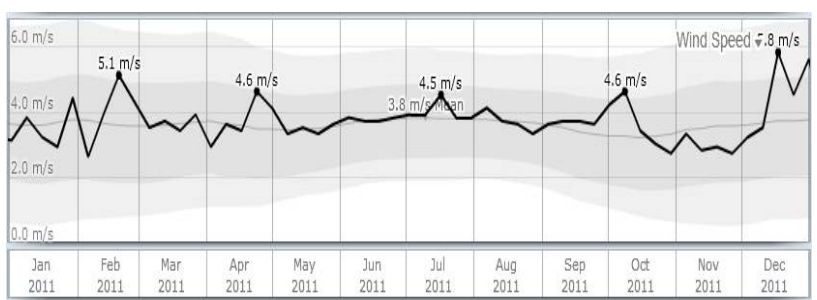

Fig. 1. Yearly average daily wind speed.

In the present studied case, the measured temperatures and solar radiation (Tab. 1) recorded over the year period of 2011 for the city of Annaba were obtained from the Algerian national meteorological office database. The monthly average amount of the total solar radiation incident on a horizontal surface for a given month is evaluated as the numerical average of 3-hourly values for the given month. The primary disadvantage of solar air heaters is the need for handling relatively large volumes of air with low thermal capacity as working fluid. They utilize both beam and diffuse solar radiation for temperatures below $60{ }^{\circ} \mathrm{C}$, and do not require sun tracking. The direct use of air as the working substance reduces the number of required system components. Specifications of the tested solar air collector are summarized in table 2 .

Table 1. Climate data for Annaba site, year 2011.

\begin{tabular}{|c|c|c|}
\hline Months & $\boldsymbol{T}_{\text {daily mean }}\left[{ }^{\circ} \mathrm{C}\right]$ & $\boldsymbol{H}_{\boldsymbol{h}}\left[\mathrm{MJ} / \mathrm{m}^{2} /\right.$ day $]$ \\
\hline Jan/Feb & 11.8 & 2.6 \\
\hline Mar. & 13.4 & 4.53 \\
\hline Apr. & 15.2 & 5.51 \\
\hline May & 18.4 & 6.69 \\
\hline Jun/Jul & 23.4 & 7.6 \\
\hline Aug. & 25.7 & 7.11 \\
\hline Sep. & 23.6 & 5.28 \\
\hline Oct. & 20.4 & 3.93 \\
\hline Nov/Dec & 14.4 & 2.3 \\
\hline
\end{tabular}

In order to minimize the heat losses, a double glazing with the thickness of $3.5 \mathrm{~mm}$ were recommended for the flat plate solar air collector under consideration. The absorber made by steel plate with an area of $(2 \times 1) \mathrm{m}^{2}$ and thickness of $0.5 \mathrm{~mm}$ was covered by black paint (Fig. 2).

Table 2. Solar air heater characteristics.

\begin{tabular}{|c|c|}
\hline Parameter & Value \\
\hline Absorber emissivity, $\varepsilon_{a}$ & 0.1 \\
\hline Absorber mean temperature, $T_{p, m}$ & $50^{\circ} \mathrm{C}$ \\
\hline Air-mass flow rate, $\dot{m}$ & $0.044 \mathrm{~kg} / \mathrm{s}$ \\
\hline Air specific heat, $C_{p}$ & $1005 \mathrm{~J} /(\mathrm{kg} \cdot \mathrm{K})$ \\
\hline Albedo of ground, $\rho$ & 0.2 \\
\hline Ambient temperature, $T_{a}$ & $28^{\circ} \mathrm{C}$ \\
\hline Collecting area, $A_{C}$ & $2 \mathrm{~m}{ }^{2}$ \\
\hline Collector efficiency, $F^{\prime}$ & 0.75 \\
\hline Collector side area, $A_{e}$ & $0.4 \mathrm{~m}{ }^{2}$ \\
\hline Glass emissivity, $\varepsilon_{g}$ & 0.88 \\
\hline Insulator thermal conductivity, $k$ & $0.025 \mathrm{~W} /(\mathrm{m} \cdot \mathrm{K})$ \\
\hline Inlet air temperature, $T_{f, i}$ & $11 \div 26^{\circ} \mathrm{C}$ \\
\hline Optical efficiency, $\eta_{o}$ & 0.8 \\
\hline Stephan-Boltzmann constant, $\sigma$ & $5.7 \times 10^{-8} \mathrm{~W} /\left(\mathrm{m}^{2} \cdot \mathrm{K}^{4}\right)$ \\
\hline Thickness of bottom insulation, $L$ & $0.06 \mathrm{~m}$ \\
\hline Thickness of side insulation, $L$ & $0.03 \mathrm{~m}$ \\
\hline
\end{tabular}
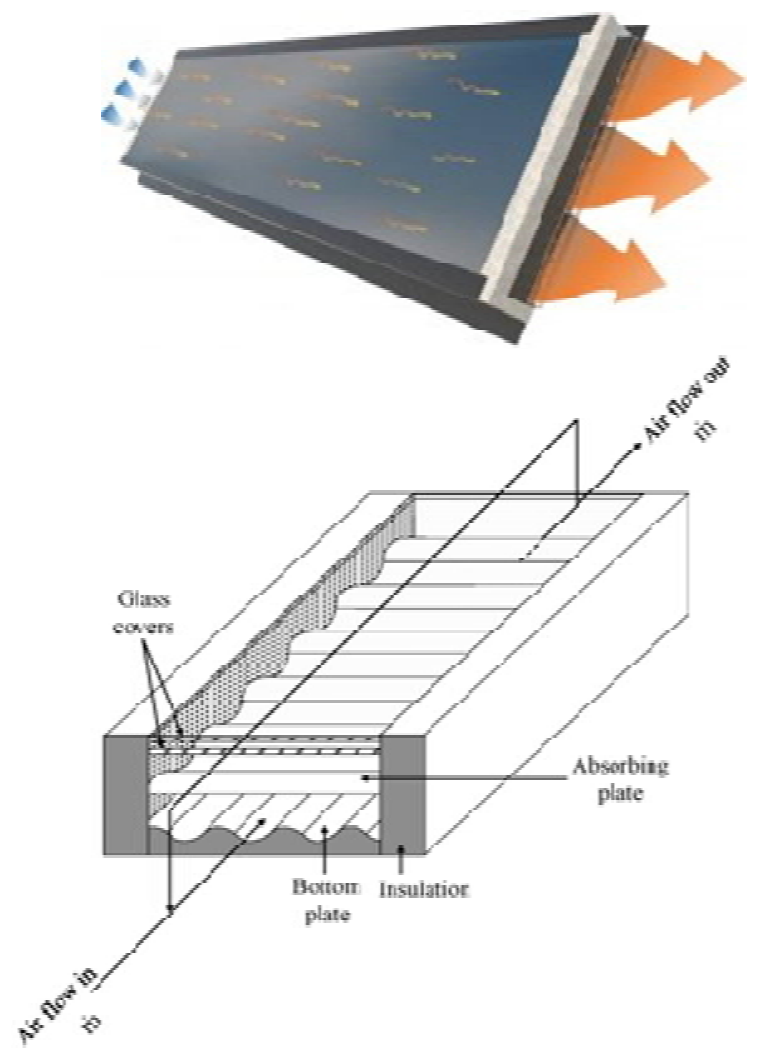

Fig. 2. Air solar collector description. 


\section{Overriding equations}

The efficiency of a solar collector is defined as the ratio of the amount of useful heat collected to the total amount of solar radiation striking the collector surface during any period of time

$$
\eta_{C}=\frac{Q_{U}}{A_{C} I_{T}}
$$

In this section various relations that are required in order to determine the useful energy collected and the interaction of the various constructional parameters on the performance of a collector are presented.

The useful energy collected from a collector can be obtained from the following formula

$$
Q_{U}=A_{C}\left[I_{T} \eta_{o}-U_{G}\left(T_{P, m}-T_{a}\right)\right]=\dot{m} C_{P}\left(T_{f, o}-T_{f, i}\right)
$$

Eq. (2) can be modified by substituting inlet fluid temperature for the average plate temperature, if a suitable correction factor is included. The resulting equation is

$$
Q_{U}=A_{C} F_{R}\left[I_{T} \eta_{O}-U_{G}\left(T_{f, i}-t_{a}\right)\right]
$$

The correction factor $F_{R}$, can be considered as the ratio of the heat actually delivered to that delivered if the collector plate were at uniform temperature equal to that of the entering fluid. $F_{R}$ is affected only by the solar collector characteristics, the fluid type and the fluid flow rate through the collector, Duffie and Beckman [10]

$$
F_{R}=\frac{\dot{m} C_{P}}{A_{C} U_{G}}\left[1-\exp \left(-\frac{A_{C} U_{G} F^{\prime}}{\dot{m} C_{P}}\right)\right]
$$

where $F^{\prime}$ is the collector efficiency.

The overall heat loss coefficient of the collector $\left(U_{G}\right)$ is the sum of the top, bottom and edges losses coefficients. Following the basic procedure of Hottel and Woertz [11], Klein [12] developed an empirical equation for the collector forwards heat loss coefficient as

$$
\begin{aligned}
& U_{t}=\frac{\frac{1}{\frac{C}{T_{P, m}}\left[\frac{T_{p, m}-T_{a}}{N_{g}+f}\right]^{e}}+\frac{1}{h_{w}}}{\sigma\left(T_{p, m}+T_{a}\right)\left(T_{p, m}^{2}+T_{a}^{2}\right)} \\
& +\frac{\frac{1}{2 N_{g}+f-1+0.133 \varepsilon_{a}}-N_{g}}{\varepsilon_{g}}
\end{aligned}
$$

Parameters in the above equation are correlated as follows

$$
f=\left(1+0.089 h_{w}-0.1166 h_{w} \varepsilon_{a}\right)\left(1+0.07866 N_{g}\right)
$$

$$
\begin{gathered}
C=520\left(1-0.00005 \beta^{2}\right) \\
e=0.43\left(1-\frac{100}{T_{p, m}}\right)
\end{gathered}
$$

A convective heat transfer coefficient, McAdams [13], for the air flowing over the outside surface of the glass cover depends primarily on the wind speed (Fig. 1)

$$
h_{w}=5.7+3.8 V_{w}
$$

The collector backwards heat loss coefficient for a unit surface is

$$
U_{b}=\frac{k}{L}
$$

The edges heat loss coefficient is given by

$$
U_{e}=\frac{k}{L^{\prime}}\left(\frac{A_{e}}{A_{c}}\right)
$$

On the other hand, the total radiation on a tilted surface per hour is calculated using the following equations from Duffie and Beckman [10]

$$
I_{T}=I_{b} R_{b}+I_{d}\left(\frac{1+\cos \beta}{2}\right)+I_{h} \rho\left(\frac{1-\cos \beta}{2}\right)
$$

where $R_{b}$ is the dimensionless ratio of solar beam radiation on a tilted surface to that on a horizontal surface

$$
R_{b}=\frac{\cos (\varphi-\beta) \cos \delta \cos \omega+\sin (\varphi-\beta) \sin \delta}{\cos \varphi \cos \delta \cos \omega+\sin \varphi \sin \delta}
$$

The solar declination according to the Julian day $n$ of the year is

$$
\delta=23.45 \sin \left(\frac{360(284+n)}{365}\right)
$$

The hourly angle from the local meridian $(\omega)$ varies at 15 degrees per hour, negative in the morning positive the afternoon.

According to Liu and Jordan [14], the hourly diffuse radiation

$$
I_{d}=\frac{\pi}{24}\left[\frac{\cos \omega-\cos \omega_{s}}{\sin \omega_{s}-\left(\frac{\pi \omega_{s}}{180}\right) \cos \omega_{s}}\right] H_{d}
$$

The hourly total solar radiation falling on a horizontal surface [15] results from the sum of hourly beam and diffuse radiations 


$$
\begin{aligned}
I_{h} & =I_{b}+I_{d} \\
& =\frac{\pi(a+b \cos \omega)}{24}\left[\frac{\cos \omega-\cos \omega_{s}}{\sin \omega_{s}-\left(\frac{\pi \omega_{s}}{180}\right) \cos \omega_{s}}\right] H_{h}
\end{aligned}
$$

$a$ and $b$ are empirical functions, expressed as

$$
\begin{aligned}
& a=0.4090+0.5016 \sin \left(\omega_{s}-\frac{\pi}{3}\right) \\
& b=0.6609-0.4767 \sin \left(\omega_{s}-\frac{\pi}{3}\right)
\end{aligned}
$$

The world radiation centre assumes for the solar constant $I_{o}$ the value of $1367 \mathrm{~W} / \mathrm{m}^{2}$ with an uncertainty of the order of $1 \%$. The equation below of the average sun irradiation outside the earth's atmosphere, is expressed as

$$
I_{o n}=I_{o}\left[1+0.033 \cos \left(\frac{360 n}{365}\right)\right]
$$

The correlation of Erbs et al. [7] is used to evaluate the daily diffuse fraction

$$
\frac{H_{d}}{H_{h}}=1.0045+0.04349 K_{t}-3.5227 K_{t}^{2}+2.6313 K_{t}^{3}
$$

$K_{t}$ is an hourly clearness index and can be defined as the ratio of the total solar radiation to the extraterrestrial radiation for that specific hour

$$
K_{t}=\frac{H_{h}}{H_{o}}=\frac{H_{b}+H_{d}}{H_{o}}
$$

where:

$$
H_{o}=\frac{86400}{\pi} I_{o n} \cos \varphi \cos \delta\left(\sin \omega_{s}-\frac{\pi \omega_{s}}{180} \cos \omega_{s}\right)
$$

$\omega_{s}$ is the sunset hourly angle, given as

$$
\omega_{s}=\arccos (-\tan \varphi \tan \delta)
$$

$K_{t}$ is estimated for the monthly typical day (Fig. 3). The day-type of the month is the day for which the declination is closest to the average declination of this month.

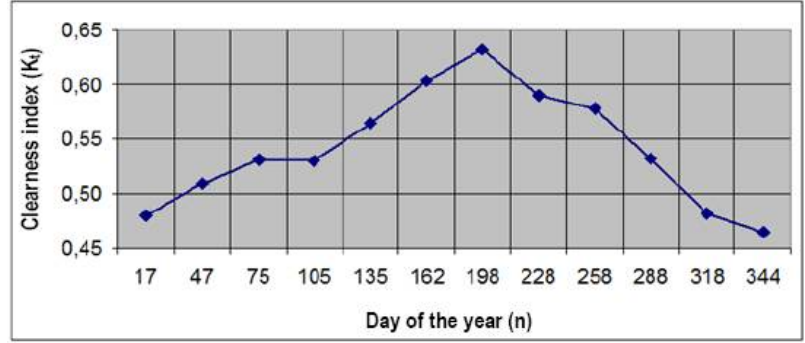

Fig. 3. Clearness index year evolution for typical days.

\section{Results and analysis}

A wide collector tilt range was used in function of different south orientations. The Following graphs were drawn by using average values of radiation for each month.

The comparison shown in figure 4 between daily solar radiation on earth and extraterrestrial radiation on a horizontal surface, confirm that the solar radiation before entering earth atmosphere is integral, this correspond to the highest curve. Thereafter, the attenuation occurring is due to reflexion, diffusion and absorption by gases and particles present in earth atmosphere. Sometimes, the diminution reaches $50 \%$ of the total value of extraterrestrial radiation.

Curves plotted in figure 5 are similar to above ones, they illustrate the hourly total solar radiation and its components diffuse and beam, on a horizontal surface. Peaks are noticed during summer for total and beam radiation, however diffuse radiation is constant almost the year.

In order to calculate the collector efficiency, a heat balance is used in which the absorbed solar-ray needs to be calculated. Detailled behaviour of the ratio of beam radiation on the tilted surface to that on horizontal surface $\left(R_{b}\right)$ is studied in figure 6, where it is clearly shown the same profile evolution of $R_{b}$ function. During winter it is very high as the sun is low on the sky. It can cause high results during winter periods.

Yearly useful power evolution is presented on figure 7 where a similarity of curves profile can be seen. Tilts between $15^{\circ}$ and $30^{\circ}$ provide the best useful power, the maximum is reached in August with a values exceeding 4300 Watt when the air solar collector is facing south. It is clearly visible for tilts upper to $45^{\circ}$ the decrease in the intensity of the collector delivered power. However, tilting angles from $30^{\circ}$ to $45^{\circ}$ are even acceptable for lower azimuth angles. Globally, the overall power decreases when the azimuth angle $(\gamma)$ increases, modifying the curves by increasing the gap between them.

The figure 8 shows how change the efficiency across each month. This efficiency is higher during the summer months and lower during the winter months because during the summer the energy that arrives to the solar collector is higher than winter. In summer the intensity of the energy that arrives to the solar collector is higher and 
longer and this is the most important reason of this difference. During summer the energy transferred to airflow is bigger as the air is at low temperature and gains much heat from the sun. The sun radiation is more stable, so the efficiency is similar at this time of year. Regardless of the orientation, it is noticeable that for $\gamma=0^{\circ}$ and $22.5^{\circ}$ the collector efficiency is approximately constant over a long period, from March to October.

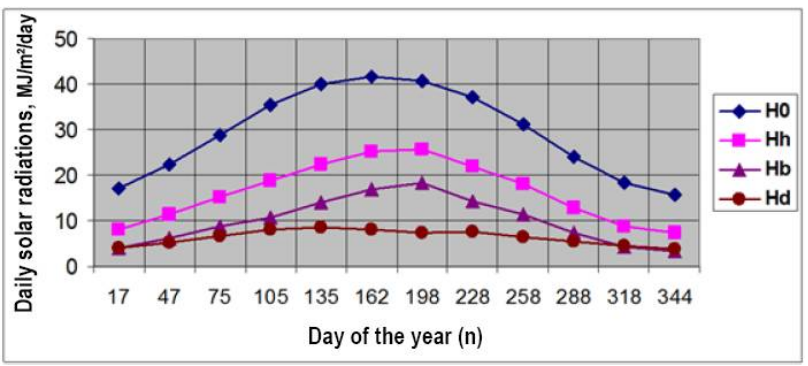

Fig. 4. Daily solar radiations for typical days.

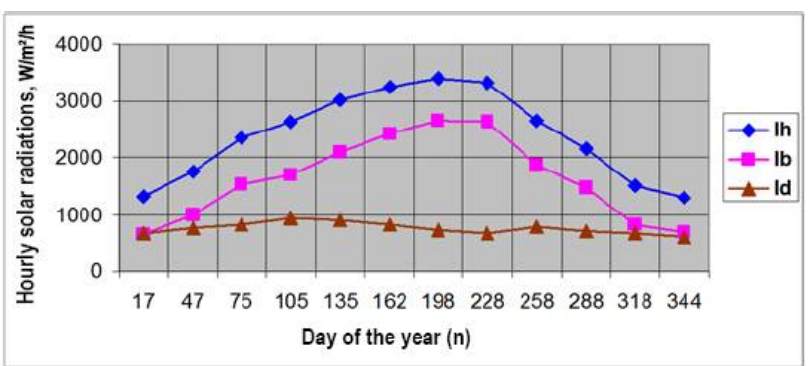

Fig. 5. Hourly solar radiations estimation.

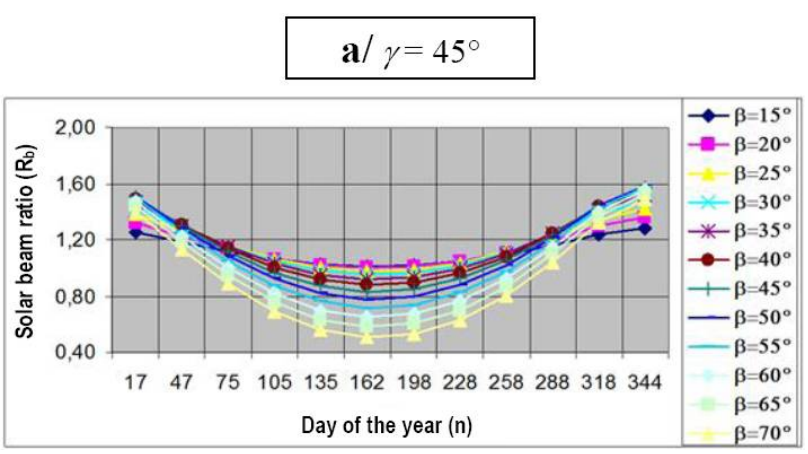

$$
\text { b/ } \gamma=67.5^{\circ}
$$

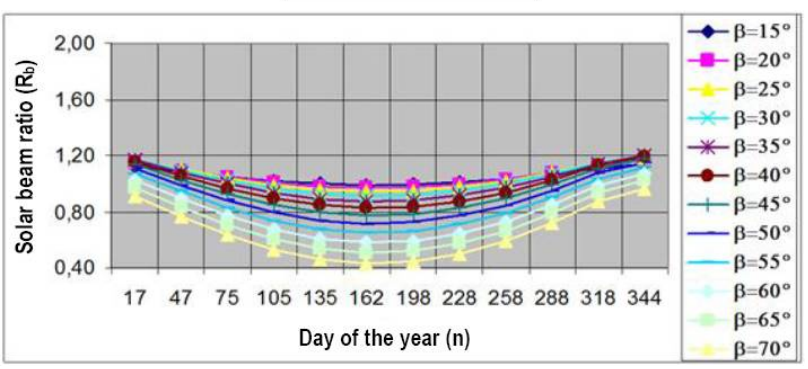

Fig. 6. Ratios of beam radiation on a tilted surface to that on a horizontal surface $(a, b)$.

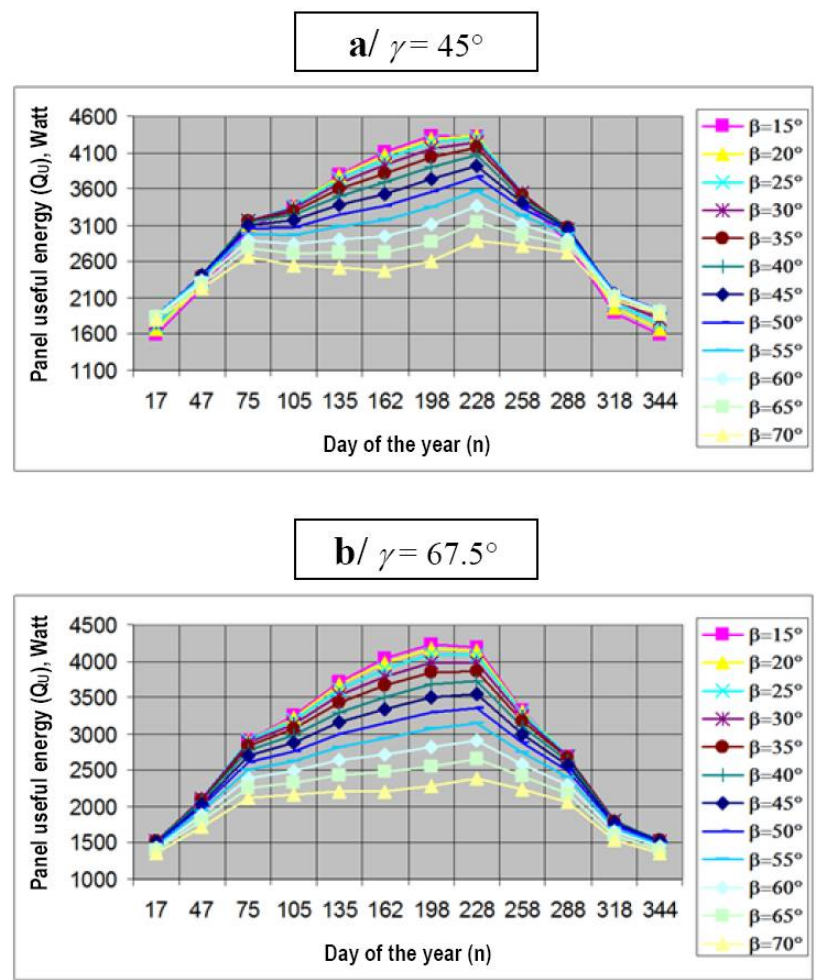

Fig. 7. Yearly air solar heater useful power (a, b).

$$
\text { a/ } \gamma=45^{\circ}
$$

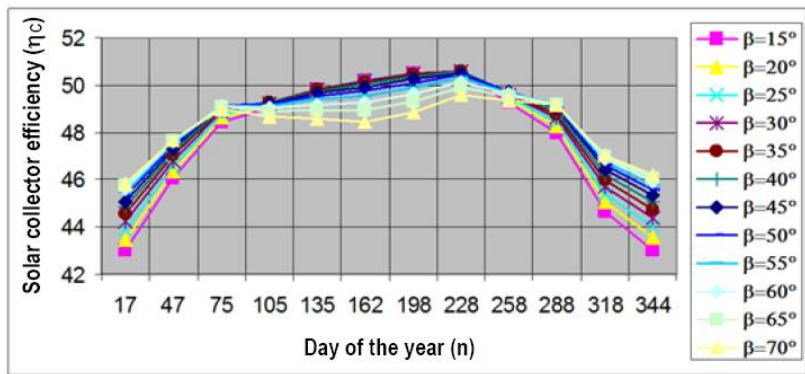

$$
\text { b/ } \gamma=67.5^{\circ}
$$

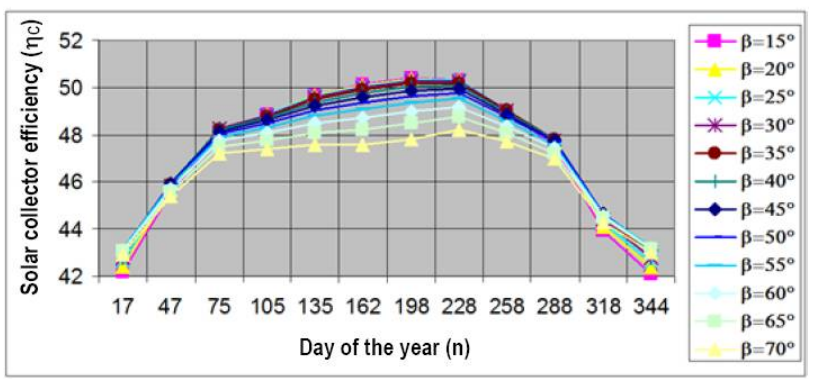

Fig. 8. Yearly collector efficiency (a, b). 


\section{Conclusions}

Knowing the measured global-horizontal radiation $H_{h}$, a numerical calculation was performed to study and analyze the influence of tilt and orientation on the thermal performance of a solar air flat plate collector with a double glass cover.

Solar collectors need to be inclined at the optimum angle to maximize the receiving energy. The purpose of the paper was the optimisation of the solar collector position within a wide range of tilts compared with a given orientation.

The yearly clearness index evolution seems to be a parabolic function with the maximum point recorded in July. Obviously, $K_{t}$ goes down during months when weather is bad. Increasing the tilt has the effect of decreasing the useful energy absorbed, however lower tilts are recommended if solar collectors cannot be oriented south.

However, the system designer may not necessarily be interested in an annually optimal solar collector orientation, but rather, an optimal orientation at a specific time period where there is an energy production deficit. This study can be expanded to determine optimal collector orientations for specific time periods of the day and season.

\section{References}

1. A.S. Abdullah, M.K. Bassiouny, Energy Conversion and Management 88, 88-95 (2014)

2. H.F. Öztop, M.M. Rahman, A. Ahsan, M. Hasanuzzaman, R. Saidur, K. Al-Salem, N.A. Rahim, Int. J. Heat Mass Transfer 55, 1844-1854 (2012)

3. S.A. Klein, W.A. Beckman, J. Solar Energy Eng. 106, 393-402 (1984)

4. H.M. Yeh, T.T. Lin, Energy, 21, 6, 435-443 (1996)

5. A. Abene, V. Dubois, M. Le Ray, A. Ouagued, J. Food Eng. 65, 15-22 (2004)

6. H. Mzad, Archives of Thermodynamics 29, 1, 71-86 (2008)

7. D.G. Erbs, S.A. Klein, J.A. Duffie, Solar Energy 28, 4, 293-302 (1982)

8. R. Tang, T. Wu, Applied Energy 79, 3, 239-248 (2004)

9. M.J. Ahmad, G.N. Tiwari, The Open Renewable Energy J. 2, 19-24 (2009)

10. J.A. Duffie, W.A. Beckman, Solar Engineering of Thermal Processes ( $2^{\text {nd }}$ edition, Wiley, New York, 1991)

11. H.C. Hottel, B.B. Woertz, Transactions of the ASME 64, 64-91 (1942)

12. S.A. Klein, Solar Energy 17, 79-80 (1975)

13. W.H. McAdams, Heat Transmission $\left(3^{\text {rd }}\right.$ edition, McGraw-Hill, New York, 1954)
14. B.Y.H. Liu, R.C. Jordan, Solar Energy 7, 2, 53-74 (1963)

15. M. Collares-Pereira, A. Rabl, Solar Energy 22, 155164 (1979) 